\title{
Methodology of Competitive Positioning of Types of Economic Activities of the Territory
}

\author{
Safiullin A. R. ${ }^{1} \&$ Salahieva M. F. \\ ${ }^{1}$ Institute of Management, Economics and Finance, Kazan Federal University, Kazan, Russia \\ Correspondence: Safiullin A. R., Institute of Management, Economics and Finance, Kazan Federal University, \\ Kazan, 420008, Russia. Tel: 7-843-291-1360. E-mail: safiullin.ar@gmail.com
}

Received: December 27, 2014

Accepted: February 19, 2015 Online Published: April 30, 2015

doi:10.5539/ass.v11n11p68

URL: http://dx.doi.org/10.5539/ass.v11n11p68

\begin{abstract}
The article comprises methodological approach to positioning and assessment of competitive advantages of profile types of economic activity of the territory on the basis of matrix model. Matrix competitive positioning is based on two integral indicators - competitive advantages of factors of production and the attractiveness of the industry market. The authors propose to identify the most important sector for the regional economy based on the analysis of the coefficients of localization and concentration, as well as the structure of the industrial structure and trends of change in the case of the Republic of Tatarstan.
\end{abstract}

Keywords: region's economic area, regional competition, regional competitive advantages, competitive positioning, economic activities, industrial enterprise's resource potential, economic area "growth points"

\section{Introduction}

An essential stage of a territory's competitiveness research is comparative competitor analysis by certain aspects which allows to identify the competitive position of a territory and to assess the level of its competitiveness in industry markets. With this in view competitive positioning determines the attractiveness of industry markets (in terms of development dynamics, competitive intensity, the level of concentration and localization, administrative burden etc.) and identifies the main competitors. Its practicality consists in the fact that comparative analysis estimates the importance of various competitive advantages for each industrial market, possibility and ability to operate them and management efficiency in competitive advantages development and their influence on the competitive position of a territory (Safiullin, Elshin, Prygunova, \& Galyavov, 2013; Safiullin, Safiullin, Ermolaeva, \& Noskova, 2013).

Thus, the necessity of competitive positioning is caused by the following factors:

- Adequate estimation of the efficiency of competitive interaction and the current position in each industrial market;

- Comparative analysis of present competitive position against that of competitors, determination of potential and real competitors;

- Revealing objective-subjective, stable-unstable, short-term-sustainable competitive advantages;

- Determination of strategic and operational problems in competitiveness increase and competitive advantages development;

- The targeted character of administrative influence including development of competitive advantages and possibilities, resistance to external threats.

Specialized books on strategic management may suggest various approaches to the definition of competitive positions. Many concepts universally present a competitive position as a relative category reflecting the level of competitiveness of an entity in industry. In the context of the approach considered in the present research competitive position is suggested to be determined as position of a kind of economic activity of a territory fixed for a certain point of time against that of competitors estimated by a limited set of quantitative and qualitative parameters. Accordingly positioning is the process of identification of competitive position of economic activities of a territory against that of competitors. An active competitive position is formed by implementation of a structural policy during which an efficient control of territorial competitive advantages is brought about. The 
latter changes the level of competitiveness in industrial market and determines the subsequent competitive actions.

\section{Method}

One of the most widespread methods of competitive positioning are matrix models.

Nowadays there are various modifications of matrix models: BCG, GE/McKinsey, Arthur DLittle, Shell, Abell-Hammond, Hofer-Shendel models, etc. The criteria of competitive positions in such models are competitiveness - appeal of a market or a branch (GE/McKinsey, Shell, Abell-Hammond models), a relative competitive position - a stage of the market development (Hoffer-Shendel model), relative position in the market - life cycle stages (Arthur DLittle model).

Matrix models consider both internal (competitiveness of a product, business, a strategic business district) and external factors (appeal of a market, a branch).

Analyzing competitive positions of economic activities it is expedient to use such matrix models to estimate competitive advantages of territories by competitiveness factors (Safiullin, Safiullin, Elshin, \& Prygunova, 2014).

Analyzing competitive advantages of economic activities quantitative and qualitative indicators of competitiveness may be combined in two integral indicators which will be matrix model coordinate axes: the first one - competitive advantages by production factor, the second - appeal of an industrial market. The appeal of an industrial market may be expressed by a small group of indicators reflecting its dynamics (the rates of shipped products volume increase), financial and economic (profit, profitability, investments into a fixed capital, reserve for depreciation, wage fund) and social characteristics (average number of personnel, monthly average wage). The values of localization factor in statics and dynamics best correspond to the axes of coordinates.

According to our theoretical analysis economic literature points out three primary industrial markets characteristics: concentration, scale and differentiation of a product (Krugman, 1991). Besides the fact that each of them has an independent function their various combinations has a complex influence on branch structure specificity. For example, product differentiation and concentration influence intra-branch competition between manufacturers in prices and marginal profits. Economy of scale, product differentiation and the relevant brand loyalty determine probability of a new market entry as well as opportunity to maintain higher prices so as not to involve external competition. All three elements provide monopolistic advantages forming market entry-exit barriers. Thereby the structure can determine not only the highest price which can be set without entry threat but also probable co-operation of existing manufacturers to achieve this ceiling price avoiding a price competition among themselves. However if product differentiation can act as a single entry barrier, there is a strong interrelation between concentration and economy of scale, therefore they operate together. In this connection when managing competitive advantages in industrial markets it is required to pay attention to the independent analysis of not only the economic essence of these factors but also of interrelation between them.

Thus, concentration of production reflects relative size and quantity of manufacturers operating in an industrial market. The smaller is the number of manufacturers, the higher is the concentration level. At the same quantity of manufacturers in the market: the less they differ from each other by size, the lower is the concentration level. The result of an independent choice of output and production price made by a manufacturer is defined by the feedback of competitors acting in the market. Concentration level influences propensity of manufacturers to rivalry or cooperation: the less manufacturers act in a market, the easier it is for them to acknowledge interdependence from each other, and the more likely they will resort to cooperation. Therefore we may suggest that the higher is concentration level, the less competitive and the more monopolized will be the market.

The methodological toolbox of measures of regional concentration of industries and industrial specialization of regions are also presented in the articles of Bickenbach and Bode (2008), Aiginger and Rossi-Hansberg (2006), Conley and Dupor (2003), Arauzo-Carod, J.-M. (Arauzo-Carod, 2008; Arauzo-Carod, Liviano-Solis, \& Manjón-Antolín, 2010) etc.

Since 1982 The United States Department of Justice has used Herfindahl-Hirschman index as the basic characteristic of the industrial markets structure. This index is defined as the sum of the squares of the shipped production shares of each entity (territory) in the industrial market:

$$
H H I=\sum_{n=1}^{N} S_{n}^{2},
$$


where $S_{n}$ is a share of the industry of an $\mathrm{n}$ territory in the total country production shipped.

If the value of the index is within the range from 0 to 1000 the market is considered poorly concentrated, in the range from 1000 to 1800 - moderately concentrated, over 1800 - strongly concentrated.

When analyzing the industrial markets structure at meso-level the concentration index needs to be supplemented with localization factor:

$$
I_{L j}=\frac{D_{j k n}}{D_{j k}},
$$

where $I_{L j}$ is the factor of localization of industrial production by $\mathrm{j}$ kind of economic activity of an $\mathrm{n}$ territory;

$D_{j k n}$ is the share of shipped production of $\mathrm{j}$ kind of economic activity in the total amount of shipped production by $\mathrm{k}$ section of the Russian National Classifier of Economic Activities $(\mathrm{k}=1 ; 6)$ or by the total industry of an $\mathrm{n}$ territory;

$D_{j k}$ is the share of shipped production of $\mathrm{j}$ kind of economic activity in the total amount of shipped production by $\mathrm{k}$ section of the Russian National Classifier of Economic Activities $(\mathrm{k}=1 ; 6)$ or by the nationwide industry.

If the calculated values of the factor are greater than unity, this kind of economic activity is a profile one for the territory possessing competitive advantages and potentially attractive for the further development (at equality 1 kind of economic activity satisfies only local demand and it is focused mainly on home market). If the localization factor is less than a unit the territory does not specialize in this kind of economic activity, internal demand is replaced mostly with import from other territories.

The estimation of localization factor dynamics is assumed to be reasonable: its growth may testify to the strengthening of competitive advantages in the industry markets and favorable prospects of development, while decrease may testify to aggravation of competition or deterioration of market conditions which will demand accelerated competitive advantages, diversification of production factors with entrance to the adjacent markets or decreased business activity in the given kind of economic activity.

The localization factor can be calculated both with magnitude of indicators (gross value added, the quantity of enterprises, basic production assets, amortization, wage fund, the number of employees, investments into fixed capital) and with their growth rates. For example, the calculation of localization factor by the quantity of employees can be carried out in the following way:

$$
I_{L j}^{l}=\frac{l_{j n} / l_{n}}{L_{j} / L},
$$

where $l_{j n}$ - the quantity of employees in $\mathrm{j}$ kind of economic activity of an $\mathrm{n}$ territory;

$l_{n}$ - the quantity of workers employed in the industry in $\mathrm{n}$ territory;

$L_{j}$ - the quantity of workers employed in $\mathrm{j}$ kind of economic activity in the country;

$L-$ the quantity of workers employed in the nationwide industry.

Localization factor enables to express a new indicator - the average size of enterprises (output for 1 enterprise the relation of production shipped and the quantity of large and average enterprises in $\mathrm{j}$ kind of economic activity).

A high level of concentration can arise due to economy of scale which allows relatively large manufacturers to turn out and sell goods with lower average costs than that of relatively small manufacturers. Some definitions even underline interrelation of concentration and economy of scale. Thus, domestic experts point out that concentration is the process of centralization of shipped production at large manufacturers to apply scale effect and agglomeration effect. In this regard the scale effect is defined as a tool of the theory of production functions - relation between changed volumes of resources used and changed related production results. The agglomeration effect is considered as economic benefits from territorial concentration of production and other economic entities (Feser \& Bergman, 2000; Gafurov, Platonova, \& Pratchenko, 2014; Nielsen \& Hennerdal, 2014).

\section{Competitive Positioning of Types of Economic Activities of the Republic of Tatarstan}

Thus, matrix is suggested to be positioned in four quadrants (Figure 1). 
According to Figure 1, the most attractive kinds of economic activity will get in quadrant II as it is characterized by high localization and its positive dynamics. Strong competitive advantages in this case will be possessed by profile kinds of economic activity for the territory. Having compared profile activities by each production factor with the economic activity position on the matrix, it is also possible to define which factor the greatest impact on the competitive position of the industry market has. If accumulation of competitive advantages in production factor is accompanied by the growth of localization factor, the given factor will be significant for a competitive position of an economic activity (Safiullin, Elstin, \& Shakirova, 2012).

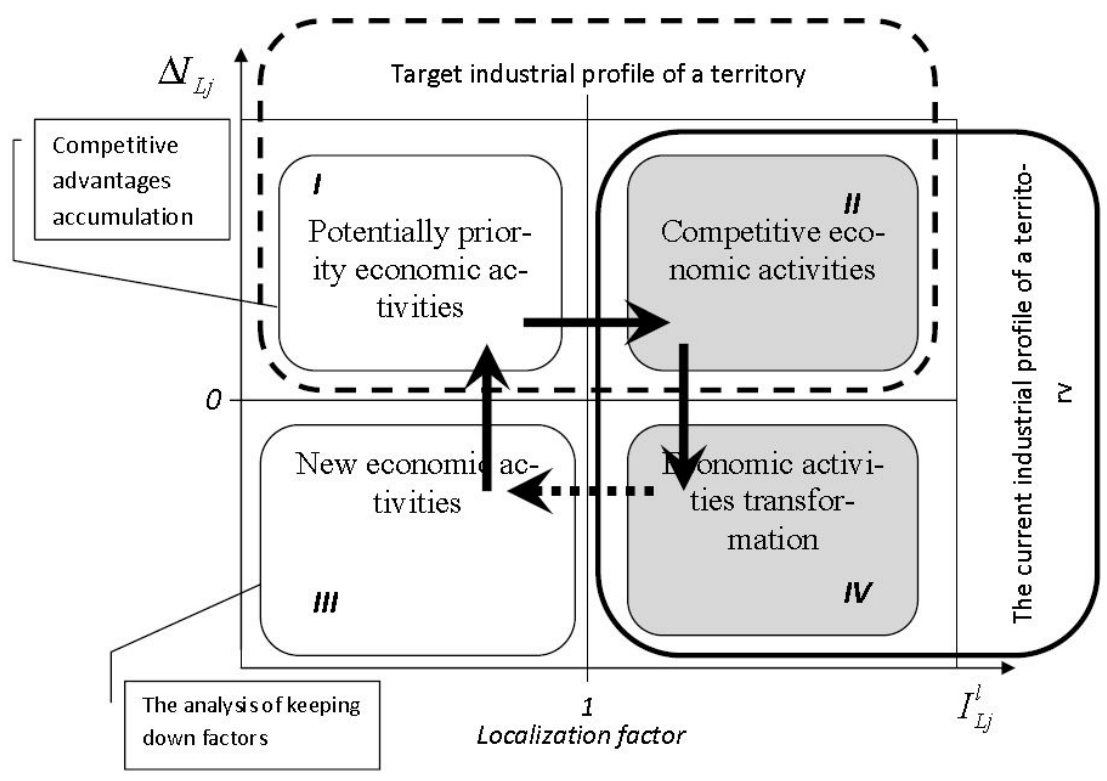

Figure 1. The matrix of territories' economic activities positioning

The analysis of matrix for several periods gives an assumption of typical strategies of development for each quadrant. Thus, for economic activities which are in quadrant I (low localization but high dynamics), offensive strategy may be recommended preliminarily - competitive advantages accumulation (with long-term tendencies being preserved). Thus it is necessary to consider technological characteristics of such economic activities, availability of the relevant adequate factors of production and infrastructure, opportunities to cooperate with enterprises within a territory as well as potential risks connected with the given kinds of activity development.

If a negative dynamics in the long-term period (for example if it is connected with the long crisis phenomena) and high localization of economic activities (quadrant IV) continue, production diversification through adjacent markets with the best indicators should be considered. However it is necessary to consider that quadrant IV may be filled with socially significant economic activities (for example, food production) which are focused, as a rule, on the internal (territorial) market and not always act as competitors of domestic producers. In addition this quadrant may include such economic activities which are direct suppliers of profile manufacturers of a territory (for example, act as an element of branch cluster providing competitive advantages by means of transaction costs) and curtailment of production aimed at these activities will affect competitive positions of the latter. Accordingly, economic activities in quadrant III (if it is not new markets with innovative products) may be neglected (waiting strategy).

\section{Results}

The analysis of the industrial profile of the Republic of Tatarstan by the localization factor calculated via the volume of the organizations' turnover has shown that the most essential influence on the region economy belongs to the following economic activities (the indicator values $>2$ ):

1. petrochemical cluster:

- synthetic rubber production (25.3488);

- manufacture of rubber tyres, tyre casings and inner tubes (15.1914);

- manufacture of plastic and synthetic resins in primary forms (6.3068);

- soap and detergents production (4.0985); 
- crude oil and casinghead gas production (3.0553);

2. machine-building cluster:

- lorries production (19.1513);

3. food cluster:

- spices and seasonings production (10.2402);

- cheese production (9.9852);

- malt production (9.5761);

4. textile cluster:

- knitted goods production (3.0006);

- footwear production (2.5955).

In 2009 appreciable strengthening of positions in the region's industrial profile structure (more than $10 \%$ localization factor increase) have occurred in the following economic activities:

- manufacture of rubber tyres, tyre casings and inner tubes (the rate of increase -3.6949);

- $\quad$ household electric devices production (1.9327);

- $\quad$ production of electrical machines and electrical equipment (1.7691);

- $\quad$ plastic products production (1.7083);

- $\quad$ production of bread and nondurable pastry (1.3675);

- $\quad$ beer production (1.1434);

- $\quad$ lorries production (1.1340).

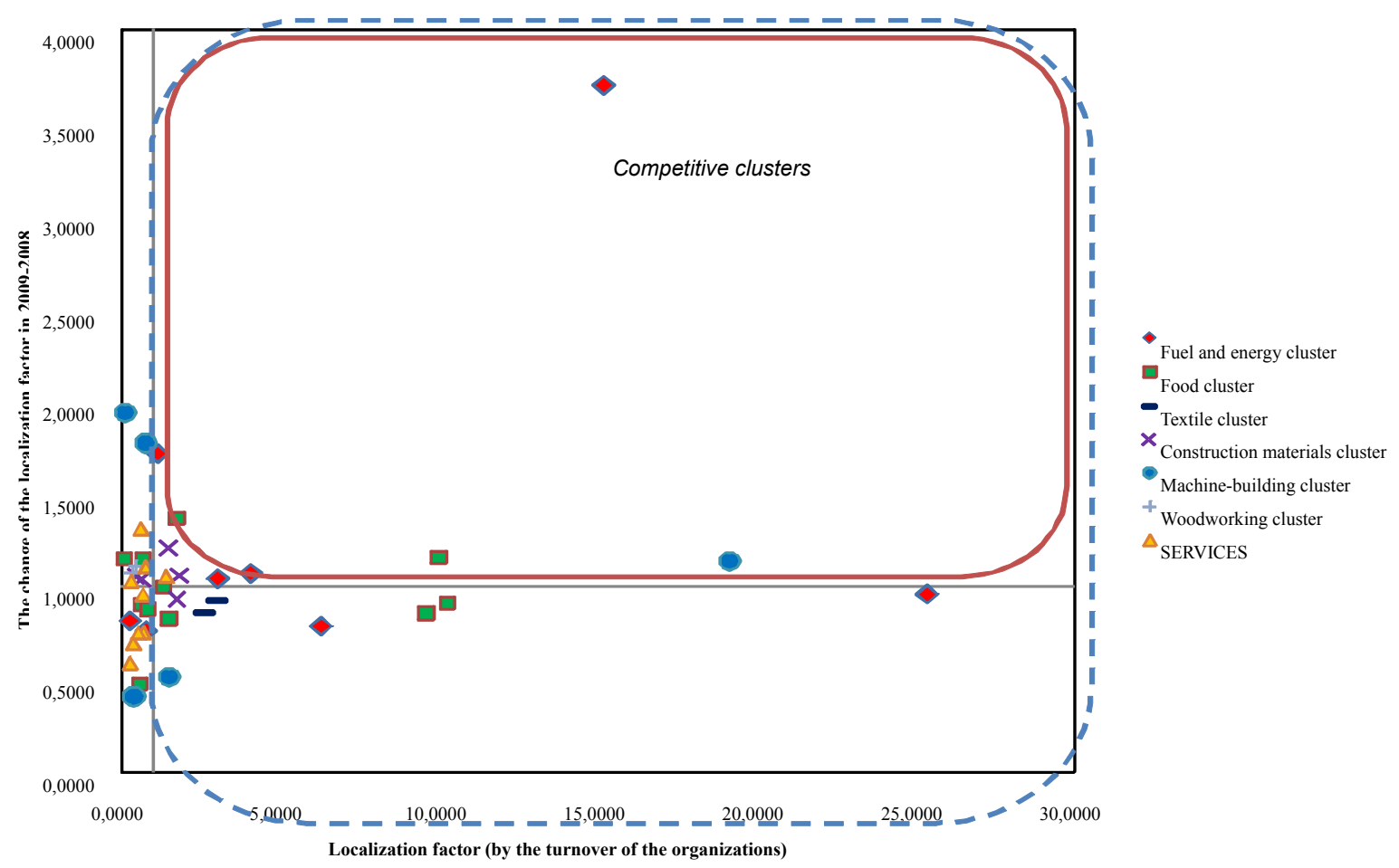

Figure 2. The structure of the RT market competitive profile in the beginning of 2010 (by the organizations' turnover) 


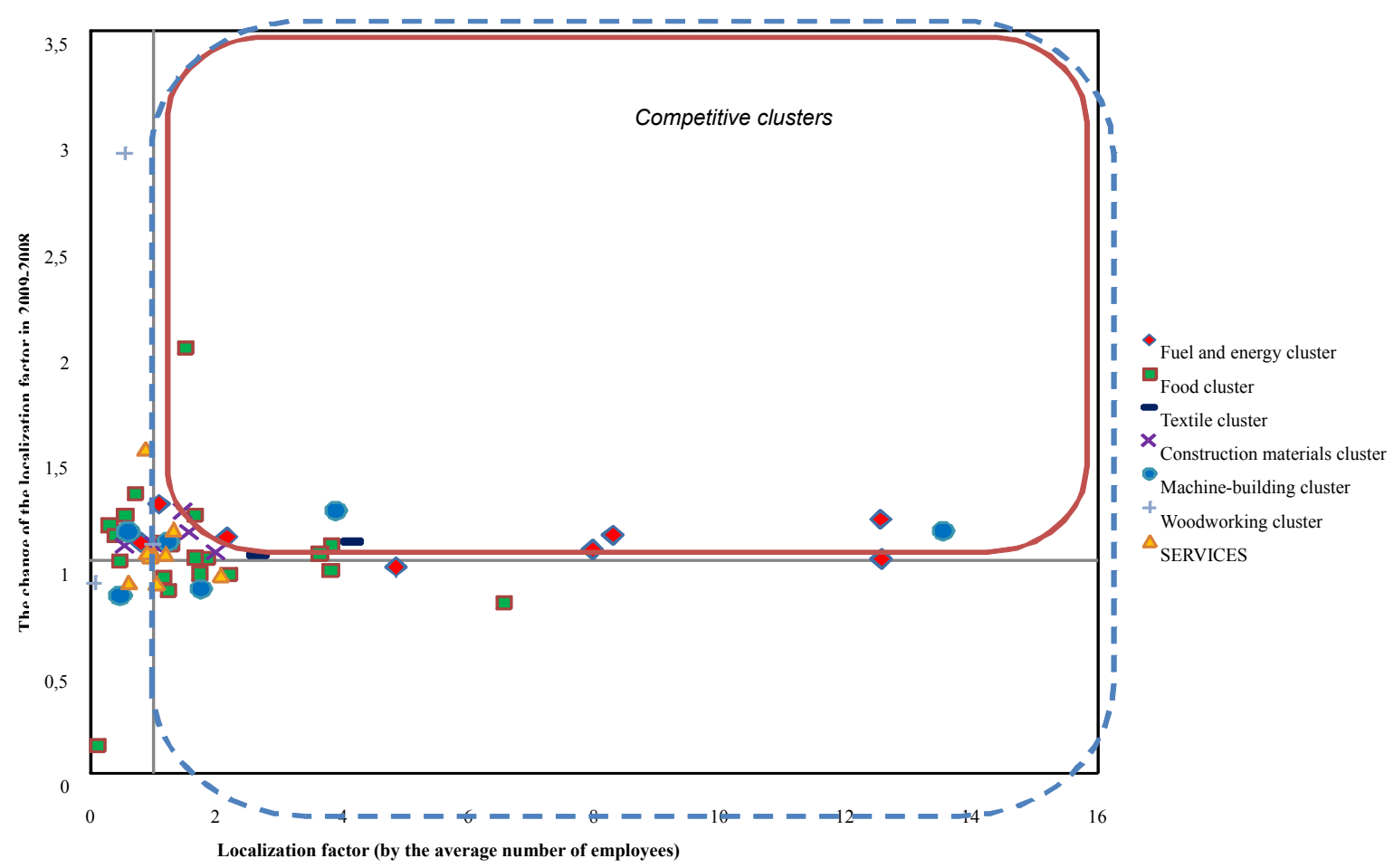

Figure 3. The structure of the RT market competitive profile in the beginning of 2010 (by the average number of employees in the organizations)

The comparative estimation of the RT industrial profile by the alternative localization factor calculated via the average number of employees confirms the profile economic activities supplementing them with the following productions:

1. machine-building cluster:

- lorries production (13.540);

- household electric devices production (3.905);

2. petrochemical cluster:

- synthetic rubber production (12.562);

- manufacture of rubber tyres, tyre casings and inner tubes (12.548);

- manufacture of plastic and synthetic resins in primary forms (8.300);

- soap and detergents production (7.978);

- crude oil and casinghead gas production; casinghead gas fractions extraction (4.857);

- petrochemicals production (2.178);

3. textile cluster:

- knitted goods production (4.145);

- footwear production (2.665);

4. food cluster:

- spices and seasonings production (6.563);

- cheese production (3.830);

- butter production (3.812);

- malt production (3.642);

- processed fluid milk production (2.196) 
Compared with 2008 the following productions have experienced an essential localization growth among profile economic activities of the Republic of Tatarstan:

- $\quad$ manufacture of vegetative refined oils and fats (the increase rate - 2.002);

- $\quad$ plastic products production (1.263);

- $\quad$ household electric devices production (1.235);

- $\quad$ production of brick, tile and other ceramic building products (1.233);

- $\quad$ production of milk, cream and other dairy products in solid forms (1 .215);

- manufacture of rubber tyres, tyre casings and inner tubes (1.193);

- $\quad$ lorries production (1.141);

- $\quad$ production of concrete, plaster and cement products (1.134);

- $\quad$ manufacture of plastic and synthetic resins in primary forms (1.119);

- $\quad$ petrochemicals production (1.111).

Localization of building industry has had a $14.4 \%$ growth.

\section{Conclusions}

In 2009 the RT economy maintained the tendency of the industrial profile structural change, with the specialization of the region in petrochemical, food and machine-building manufactures being strengthened. However despite a significant number of employees (especially in the food cluster economic activities), the turnover of many productions considerably lag behind the branch values. A fairly low efficiency characterizes also a number of machine-building (household electric devices production) and petrochemical clusters (petrochemicals production). To estimate factor features of the revealed tendencies a deeper structural analysis of competitiveness at the inter-regional level is required.

Thus, the given matrix model enables to position and estimate competitive advantages of a territory's profile economic activities revealing potential branch priorities. Similarly within the limits of each economic activity a positioning matrix may be also suggested (with other territories acting aggregately as competitors) to carry out a comparative analysis of competitive conditions of a territory.

\section{References}

Aiginger, K., \& Rossi-Hansberg, E. (2006). Specialization and concentration: A note on theory and evidence. $A$ Empirica, 33(4), 255-266.

Arauzo-Carod, J.-M. (2008). Industrial location at a local level: Comments on the territorial level of the analysis. Tijdschrift voor Economische en Sociale Geografie, 99(2), 193-208.

Arauzo-Carod, J.-M., Liviano-Solis, D., \& Manjón-Antolín, M. (2010). Empirical studies in industrial location: An assessment of their methods and results. Journal of Regional Science, 50(3), 685-711.

Bickenbach, F., \& Bode, E. (2008). Disproportionality measures of concentration, specialization, and localization. International Regional Science Review, 31(4), 359-388.

Conley, T. G., \& Dupor, B. (2003). A spatial analysis of sectoral complementarity. Journal of Political Economy, $111(2), 311-352$.

Feser, E. J., \& Bergman, E. M. (2000). National industry cluster templates: A framework for applied regional cluster analysis. Regional Studies, 34(1), 1-19.

Gafurov, I. R., Platonova, O. U., \& Pratchenko, O. V. (2014). New state economic policy - Cluster policy cluster policy as the factor of innovative development of Europe. Mediterranean Journal of Social Sciences, 5(12), 107-111.

Krugman, P. (1991). History and industry location: the case of the manufacturing belt. American Economic Review, 81(2), 80-83.

Nielsen, M. M., \& Hennerdal, P. (2014). MAUPing workplace clusters. Growth and Change, 45(2), 211-221.

Safiullin, M. R., Elshin, L. A., Prygunova, M. I., \& Galyavov, A. A. (2013). Complex analysis of prospects of the Volga Federal District regions development: Methodology and practice. World Applied Sciences Journal, 27(4), 508-511.

Safiullin, M. R., Elstin, L. A., \& Shakirova, A. I. (2012). Evaluation of business and economic activity as a 
short-term forecasting tool. Herald of the Russian Academy of Sciences, 4, 290-294.

Safiullin, M. R., Safiullin, A. R., Elshin, L. A., \& Prygunova, M. I. (2014). Matrix approach to assessing competitiveness of regions: From methodology to practice. Asian Social Science, 10, 47-56.

Safiullin, M. R., Safiullin, A. R., Ermolaeva, P. O., \& Noskova, E. P. (2013). Interdisciplinary approach to the analysis of the competiteveness types of the economic activities based on the example of the oil and gas industry (republic of tatarstan case). Middle East Journal of Scientific Research, 18(1), 42-49.

\section{Copyrights}

Copyright for this article is retained by the author(s), with first publication rights granted to the journal.

This is an open-access article distributed under the terms and conditions of the Creative Commons Attribution license (http://creativecommons.org/licenses/by/3.0/). 